\title{
Self-Defeating Humor and Negative Emotionality
}

\author{
Brittany Michelle Kester
}

Irvine Valley College (CA)

Suggested bibliographic reference

Kester, B. M. (2021). Self-defeating humor and negative emotionality. Psi Beta Journal of Research, 1(1), 28-33. https://doi.org/10.54581/VFXV5812

\begin{abstract}
The purpose of the present study was to examine the relationship between the self-defeating humor style and features of negative emotionality. Self-defeating humor is defined as humor that enhances one's relationships at the expense of the self and is described as a negative humor style, while negative emotionality is described as an overall negativity toward one's world views, outlook, self, and disposition. Four hypotheses were posed. First, it was expected that there would be a positive relationship between self-defeating humor and neuroticism. Second, it was expected that there would be a positive relationship between self-defeating humor and depression. Third, it was expected that those who prefer a self-defeating humor style would be more likely to be high in negative affectivity. Fourth, it was expected that there would be a positive relationship between self-defeating humor and an external locus of control. After acquiring Institutional Review Board approval, the study was conducted at a southern California community college. Participants read and signed an informed consent agreement at the beginning of the study and were debriefed following the study. Eighty-Nine (21 males, 68 females) volunteered to participate. Participants answered questions via an online questionnaire relating to humor styles and preferences, personality, affectivity, depression, and locus of control. Results showed support for all four hypotheses. The findings suggest that individuals who enjoy a self-defeating humor style may be more likely to experience an overall negative emotionality.
\end{abstract}

Keywords: humor, neuroticism, affect, depression, locus of control

Humor is quite possibly one of the defining traits of humanity and has continuously played a crucial role in socialization. A sense of humor is a commodity valued within all relations: friends, partners, colleagues, and more. Humor is a staple in human communication. One of the earlier definitions of humor was explained by McGhee (1971) as the perception of something being funny. From a soft quick breath forced from your nostrils accompanied by a slight smirk to a fullblown stomach aching, tear-inducing, laughter, humor itself has a wide range of variation and styles. Just as each of us harnesses our own indi- vidual traits that help define our personality so too does our sense of humor. With all the variation in both humor preference and personality, we can speculate that there may be some connection between them. The question is to what extent a specific style of humor connects with a specific personality trait. Is it possible that specific personality traits are accompanied by certain demeanor, world views, and even mental states? Could it be that individuals with certain mood disorders are more likely to prefer a certain style of humor?

Humor has not always been a priority for research, although some humor research has taken 
place. Martin et al. (2003), for example, organized humor into four different styles: self-enhancing, affiliative, aggressive, and self-defeating. This approach to categorize and define of humor contributed greater understanding of the individuals who prefer different styles of humor, humor itself, and humor's effects on different aspects of the human experience.

While researchers have studied humor's association with factors like intelligence, positive psychology, and well-being, the greatest research focus has been on personality. It was found that certain personality traits actually resonate with particular humor styles. Currently, personality is commonly examined with questionnaires having one encompassing word to represent a category of traits and characteristics. These encompassing personality traits are categorized and measured on a low to high spectrum of extraversion, agreeableness, conscientiousness, openness to experience, and neuroticism (McCrae \& Costa, 2003). With the addition of humor style categorization many studies have been conducted to measure any correlation between personality and preferred humor style. A meta-analysis consolidated these findings, and it was consistently found that neuroticism was associated with the self-defeating humor style (Mendiburo-Seguel et al., 2015), a humor style which uses humor to enhance relationships with others at the expense of the self. Further, those high in neuroticism are thought to have a higher overall likelihood to experience negative emotions similar to anxiety, depression, stress, and aggression. With its close link self-defeating humor, it is no surprise that this relationship has been consistently reflected in the research.

Another personality variable with similarities to neuroticism is termed Negative Affectivity (NA). Negative Affectivity has similar connections with the self-defeating humor style. Negative Affectivity, though similar to neuroticism, is defined as having negative emotional reactivity, aversive moods, emotional instability, and a poor self-concept (Watson et al., 1988). A study that examined humor and psychological well-being found a significant relationship between selfdefeating humor and negative affectivity. It was also found inversely that individuals low on selfdefeating humor had significantly less negative affect (Maiolino \& Kuiper, 2016). Though the study measured the effects of humor and affectivity on writing exercises, it is believed that the link between the self-defeating humor style and negative affectivity would be found if further studied.

Associations have also been found between neuroticism and negative affectivity with depression (Mineka et al., 2020). Depression is one of the most common mental disorders and has been characterized by a lack of interest or pleasure in performing activities, fluctuation in weight and sleep patterns, lethargy, and feelings of worthlessness, guilt, and poor self-concept (American Psychological Association, 2000).

Lastly, the term "external local of control" explains a generally negative emotionality and a view that life's consequences are out of one's control (Rotter,1966). When an individual expresses an external locus, they believe that much of their life is determined and controlled by outside forces over which they have little ability to influence. An external locus of control has shown a significantly positive correlation with depression (Molinari \& Khanna, 1981). This suggests a possible link to self-defeating humor and depression.

The focus of this study was the self-defeating style of humor and its link to neuroticism. Neuroticism is a blanket personality attribute linked to negative affectivity, depression, and an external locus of control. This research imposed four hypotheses. First, there would be a positive relationship between self-defeating humor and neuroticism. Second, there would be a positive relationship between self-defeating humor and depression. Third, those who prefer a self-defeating humor style would be more likely to be high in negative affectivity. Fourth, there would be a positive relationship between self-defeating humor and external locus of control. 


\section{Method and Procedure}

Eighty-nine (21 males, 68 females), introductory psychology students participated in the present study. The original participant count was 96. But seven sets of participant data were removed due to being under 18 years of age, resulting in 89 participants. The participant pool was gathered from a community college in southern California. The study, which used a correlational design, was conducted with the approval of the college's Institutional Review Board. Participants were informed of our study through an announcement email delivered by psychology professors about the study's availability using the Sona system (a data collection, management, and storage software system). Google forms was used as a survey platform and once the questionnaire was completed, participant data was integrated into the Sona system. All participants granted informed consent before beginning the questionnaire. After finishing the questionnaire, participants were debriefed and informed of the study's purpose and hypotheses. Participants were then asked to report their age, sex, race, and relationship status. Self-defeating humor was measured using the Humor Styles Questionnaire, a 32-item self-report measure using a 7-point Likert-type scale (HSQ; Martin et al., 2003). Neuroticism was measured using an adapted version of The Big 5 Inventory, a 44-item self-report measure using a 7-point Likert-type scale; only the Neuroticism subscale was used (BFI; McCrae \& Costa, 2003). Depression was measured using the Beck Depression Inventory, a 21-item self-report measure using 4-point Likert-type scale (BDI; Beck et al.,
1996). Affectivity was measured using the Positive Affect Negative Affect Schedule, a 20-item self-report measure using a 7-point Likert-type scale (PANAS; Watson, Clark, \& Tellegen, 1988). Locus of control was measured using the Locus of Control Scale, a 29-item self-report measure using a continuous scale (LCS; Rotter, 1966).

\section{Results}

There was a significant positive relationship between self-defeating humor and neuroticism, $r(87)=.28, p<.01$. That is, those who tended to prefer self-defeating humor were more likely to be higher in neuroticism than those who tended to have another humor preference. There was a significant positive relationship between selfdefeating humor and negative affect, $r(87)=.40$, $p<.001$. That is, those who tended to prefer selfdefeating humor were more likely to be higher in negative affect than those who tended to have another humor preference. There was a significant positive relationship between self-defeating humor and depression, $r(87)=.43, p<.001$. That is, those who tended to prefer self-defeating humor were more likely to have higher depressive symptoms than those who tended to have another humor preference. Finally, there was a significant positive relationship between self-defeating humor and an external locus of control, $r(87)=.30$, $p<.01$. That is, those who tended to prefer selfdefeating humor were more likely to have an external locus of control than those who tended to have another humor preference. See Table 1 for means and standard deviations on all primary variables. 
Table 1

Means and Standard Deviations on All Variables

\begin{tabular}{cccccc}
\hline Variables & $\begin{array}{c}\text { Self-Defeating } \\
\text { Humor }\end{array}$ & Neuroticism & $\begin{array}{c}\text { Negative } \\
\text { Affect }\end{array}$ & Depression & $\begin{array}{c}\text { External Locus of } \\
\text { Control }\end{array}$ \\
Mean & 3.598 & 4.271 & 3.364 & 10.714 & 12.549 \\
$\begin{array}{c}\text { Standard } \\
\text { Deviations }\end{array}$ & 1.141 & 1.177 & 1.274 & 9.077 & 3.962 \\
\hline
\end{tabular}

Note. Self-Defeating Humor was measured using the Humor Styles Questionnaire (HSQ; Martin et al., 2003); Neuroticism was measured using The Big 5 Inventory (BFI; McCrae \& Costa, 2003); Negative Affect was measured using the Positive and Negative Affect Schedule (PANAS; Watson et al., 1988); Depression was measured using the Beck's Depression Inventory (BDI; Beck et al., 1996); Locus of Control was measured using the Locus of Control Scale (LCS; Rotter, 1966).

\section{Discussion}

The four hypotheses posed in this study were confirmed, some of which support past research. The positive correlation found between the selfdefeating humor style and neuroticism was shown to be consistent within a meta-analysis of 15 studies examining the connections between personality and humor preference (Mendiburo-Seguel et al., 2015). This finding gives further evidence to the association between self-defeating humor and neuroticism. Previous research focused on the relationship between the self-defeating humor style and negative affectivity found that as the preference for self-defeating humor increased, negative affect increased as well (Maiolino \& Kuiper, 2016). Though not a meta-analysis, the current study replicated these findings and adds to the current evidence of an association between the self-defeating humor style and negative affectivity. The finding of a positive correlation between self-defeating humor and depression aligns with a study in which memes were used to depict a depressive sense of humor were more favored by participants experiencing depressive symptoms than participants in a neutral control group (Akram et al., 2020). My findings also support Cheng et al. (2013) who found a possible relationship between external local of control and the self- defeating humor style. This study's finding adds to the body of research.

Though the current study was conducted with the utmost care and caution there were possible limitations present. One potential limitation involved the sample who volunteered to participate and the unequal distribution of predominantly female participants. This may affect the generalizability of the results of this research. Another possible limitation is the average age of the participants in this study and may affect the generalizability to other generations or ages. Further research on humor preference using the Humor Styles Questionnaire could prove useful comparing different generations and across sex and could shed light on generalizability of the present findings (Martin, et al., 2003).

Considering the links between past research and the results of the current study, it is crucial to examine possible explanations for the relationships found. The first hypothesis focused on the relationship between neuroticism and the selfdefeating humor style. Neuroticism, for example, may contain in essence, a self-defeating sub-trait. This would imply that those high in neuroticism may also be high in an overall self-defeating outlook making the use self-defeating humor the preferred type of humor. Similarly, negative affec- 
tivity may also exist under the blanket of neuroticism and self-defeat. With this possibility it is suggested that negative affectivity, being an overall negative outlook, would resonate with a negative humor style. Self-defeatism may even be considered synonymous with a negative affect or life outlook and this similarity may be the link to desiring self-defeating humor as an introspective way to cope with an individual's negativity. The correlation found between depression and selfdefeating humor may be explained by an individual's need, but inability, to socialize. Individuals suffering from depressive symptoms often withdraw themselves from social relationships and struggle with social situations. The use of selfdefeating humor may be a mechanism to feel a sense of intimacy with others and alleviate some of the social isolation felt by the suffering individual. Additionally, an individual using selfdefeating humor may not acknowledge the issues they suffer from but use humor to make light of or distract from uncomfortable but needed social contact. Lastly, when examining the relationship between self-defeating humor and an external locus of control, it is suggested that the connection is related to the lack of control one feels they have in life. When an individual believes their life is out of their control, it is possible that this is a form of self-defeatism. With this possibility, it may be that individuals who feel a lack of control may see the self-defeating humor style as a way to alleviate some of the tension caused by perceived external forces in their life. It is also possible that the self-defeating humor style makes one feel a form of comfort with life's unpredictability. The overall findings may suggest that the Humor Styles Questionnaire could be an alternate form to measure aspects of negative emotionality.

\section{References}

Akram, U., Drabble, J., Cau, G., Hershaw, F., Rajenthran, A., Lowe, M., \& Ellis, J. G. (2020). Exploratory study on the role of emotion regulation in perceived valence, humour, and beneficial use of depressive internet memes in depression. Scientific Reports, 10(1). https://doi.org/10.1038/s41598-020-57953-4

Beck, A.T., Steer, R.A., \& Brown, G.K. (1996). Manual for the Beck Depression Inventory-II. San Antonio, TX: Psychological Corporation. Cheng, C., Cheung, S. F., Chio, J. H., \& Chan, M. P. (2013). Cultural meaning of perceived control: a meta-analysis of locus of control and psychological symptoms across 18 cultural regions. Psychological Bulletin, 139(1), 152 188. https://doi.org/10.1037/a0028596

Maiolino, N., \& Kuiper, N. (2016). Examining the impact of a brief humor exercise on psychological well-being. Translational Issues in Psychological Science, 2(1), 4-13. https://doi.org/10.1037/tps0000065

Martin, R. A., Puhlik-Doris, P., Larsen, G., Gray, J., \& Weir, K. (2003). Individual differences in uses of humor and their relation to psychological well-being: Development of the Humor Styles Questionnaire. Journal of Research in Personality, 37(1), 48-75.

McCrae, R. R., \& Costa, P. T., Jr. (2003). Personality in Adulthood: A Five-Factor Theory Perspective (2nd ed.). Guilford Press. https://doi.org/10.4324/9780203428412

McGhee, P. E. (1971). Development of the humor response: A review of the literature. Psychological Bulletin, 76(5), 328-348. https://doi.org/10.1037/h0031670

Mendiburo-Seguel, A., Páez, D., \& MartínezSánchez, F. (2015). Humor styles and personality: A meta-analysis of the relation between humor styles and the Big Five personality traits. Scandinavian Journal of Psychology, 56(3), 335-340. https://doi.org/10.1111/sjop.12209

Mineka, S., Williams, A. L., Wolitzky-Taylor, K., Vrshek-Schallhorn, S., Craske, M. G., Hammen, C., \& Zinbarg, R. E. (2020). Five-year prospective neuroticism-stress effects on major depressive episodes: Primarily additive 
effects of the general neuroticism factor and stress. Journal of Abnormal Psychology, 129(6), 646.

Molinari, V., \& Khanna, P. (1981). Locus of control and its relationship to anxiety and depression. Journal of Personality Assessment, 45(3), 314-319.

https://doi.org/10.1207/s15327752jpa4503_14

Rotter, J. B. (1966). Generalized expectancies for internal versus external control of reinforcement. Psychological Monographs: General and Applied, 80(1), 1-28.

https://doi.org/10.1037/h0092976
Watson, D., Clark, L. A., \& Carey, G. (1988). Positive and negative affectivity and their relation to anxiety and depressive disorders. Journal of Abnormal Psychology, 97(3), 346.

Watson, D., Clark, L. A., \& Tellegen, A. (1988). Development and validation of brief measures of positive and negative affect: the PANAS scales. Journal of Personality and Social Psychology, 54(6), 1063. 